\title{
Risk Factors for Falls in Older Adults Experiencing Homelessness: Results from the HOPE HOME Cohort Study
}

\author{
Elizabeth Abbs, $\mathrm{MD}^{7}$, Rebecca Brown, $\mathrm{MD}, \mathrm{MPH}^{2,3,4}$, David Guzman, $\mathrm{MSPH}^{5,6}$, \\ Lauren Kaplan, $P h D^{5,6}$, and Margot Kushel, $M D^{5,6}$ (D)
}

${ }^{7}$ School of Medicine, University of California, San Francisco, San Francisco, CA, USA; 2Division of Geriatrics, University of California, San Francisco, San Francisco, CA, USA; ${ }^{3}$ Division of Geriatric Medicine, Perelman School of Medicine at the University of Pennsylvania, Philadelphia, PA, USA; ${ }^{4}$ Corporal Michael J. Crescenz Veterans Affairs Medical Center, San Francisco, CA, USA; ${ }^{5}$ UCSF Division of General Internal Medicine at Zuckerberg San Francisco General Hospital and Trauma Center, San Francisco, CA, USA; ${ }^{6}$ Center for Vulnerable Populations, University of California, San Francisco, San Francisco, CA, USA.

BACKGROUND: More than half of homeless adults are of age $\geq 50$ years. Falls are a common cause of morbidity in older adults in the general population. Risk factors for falls in the general population include poor health, alcohol use, and exposure to unsafe environments. Homeless adults aged $\geq 50$ have a high prevalence of known risk factors and face additional potential risks.

OBJECTIVES: To examine the prevalence of and risk of falling in a cohort of older homeless adults.

DESIGN: Longitudinal cohort study with participant interviews every 6 months for 3 years; data were analyzed using generalized estimating equations (GEEs).

PARTICIPANTS: Three hundred fifty adults aged $\geq 50$, homeless at study entry, recruited via population-based sampling.

MEASURES: The dependent variable is any falls in prior 6 months; independent variables include individual (i.e., illness, behaviors) and social/environmental (i.e., social support, experiencing violence, living unsheltered) factors.

RESULTS: Over three quarters of participants were men (77.1\%) and Black (79.7\%). The median age was 58 (IQR $54,61)$. At baseline, one third $(33.7 \%)$ reported a fall in the prior 6 months. At follow-up visits, $23.1 \%$ to $31.2 \%$ of participants reported having fallen. In GEE models, individual risk factors (non-Black race, being a women, older age, functional impairment, urinary incontinence, history of stroke, and use of assistive devices, opioid, and marijuana) were associated with increased odds of falls. Environmental and social factors (spending any nights unsheltered (adjusted odds ratio $(\mathrm{AOR})=1.42, \mathrm{CI}=1.10$ 1.83) and experiencing physical assault $(\mathrm{AOR}=1.67$, $\mathrm{CI}=1.18-2.37)$ were also associated.

CONCLUSIONS: Older homeless adults fall frequently. Likely contributors include having a high prevalence of conditions that increase the risk of falls, compounded by heightened exposure to unsafe environments. Fall prevention in this population should target those at highest risk and address modifiable environmental conditions. Providing shelter or housing and addressing substance use could reduce morbidity from falls in homeless older adults.

$\overline{\text { Prior Presentations This study was presented at the Society of General }}$ Internal Medicine Annual Meeting, May 2019.

Received August 28, 2019

Revised November 13, 2019

Accepted January 3, 2020

Published online January 21, 2020
KEY WORDS: homelessness; vulnerable populations; falls.

J Gen Intern Med 35(6): 1813-20

DOI: $10.1007 / \mathrm{s} 11606-020-05637-0$

๑) Society of General Internal Medicine 2020

\section{INTRODUCTION}

In the USA, over half a million people experience homelessness each night ${ }^{1}$. The proportion of single homeless adults over age 50 is increasing ${ }^{1}$. Homeless adults aged 50 and over experience a higher prevalence of geriatric conditions (e.g., falls, urinary incontinence, and functional, sensory, and cognitive impairments) than adults 20 years older in the general population ${ }^{2},{ }^{3}$.

In the general population, falls are prevalent, occurring in approximately one third of adults aged 65 or older ${ }^{4}, 5$. Falls are associated with adverse outcomes including restricted mobility, deconditioning, and loss of independence ${ }^{6}, 7$. In the USA, medical costs due to fatal and non-fatal falls are approximately $\$ 50$ billion a year ${ }^{5}$. Individual risk factors for falls include medical problems (e.g., stroke, depression, functional and cognitive impairment), health-related behaviors (e.g., tobacco or alcohol use) ${ }^{8}{ }^{11}$, and social factors (e.g., lack of social support). Environmental triggers are factors external to the individual that heighten the risk of slipping or tripping. These include surface- (e.g., uneven exteriors, obstructive ground-level objects), ambient- (e.g., poor lighting), and weather-related conditions ${ }^{12},{ }^{13}$.

Falls result from an interaction between an individual's underlying vulnerabilities and their exposure to environmental conditions ${ }^{8},{ }^{14}$. People experiencing homelessness have a high prevalence of factors known to be associated with falls in the general population, including chronic diseases, functional impairment, and alcohol and opioid use problems ${ }^{2},{ }^{15}$. Homeless older adults have a high prevalence of other factors that could be associated with falls, such as substance use and heightened exposure to physical violence ${ }^{15}, 16$.

People who are homeless live in a variety of environments, including homeless shelters and unsheltered spaces that expose them to environmental hazards and violence. In each of these settings, homeless individuals have limited control over 
their environment, especially when living in unsheltered environments.

We examined the prevalence of and risk factors for falls in a longitudinal cohort of adults aged 50 and older who were homeless at study entry. We hypothesized that homeless adults would have a high prevalence of falls and high exposure to environmental hazards. We hypothesized that factors known to be associated with falls in the general population would be associated with falls in our cohort. We further hypothesized that several factors that are plausibly related, but have not been studied (use of marijuana and stimulants, exposure to physical assault, and uncontrolled environments), would be associated.

\section{METHODS}

\section{Study Overview}

We conducted a 3-year prospective cohort study of 350 homeless adults aged 50 and older, the Health Outcomes in People Experiencing Homelessness in Older Middle agE (HOPE HOME) study ${ }^{17}$. We interviewed participants at baseline and every 6 months for 3 years; at each interview, trained research staff administered a structured interview and conducted clinical assessments. The institutional review board of the University of California, San Francisco approved this study. The datasets we analyzed during the current study are available from the corresponding author on request.

\section{Study Sample}

Between July 2013 and June 2014, we recruited 350 adults aged 50 or older who were homeless at study entry. We recruited from all local shelters open to older adults $(n=5)$, all free and low-cost meal programs that served at least three meals a week $(n=5)$, one recycling center, and areas where adults slept unsheltered in Oakland, California (Fig. 1). To create a sample that best represented the target population, including the high number of people living unsheltered in Oakland, we randomly selected potential participants using sampling frames that included encampment sites, recycling centers, shelters, and meal programs ${ }^{18}$. We describe our methods in more detail elsewhere ${ }^{17-19}$.] $\rightarrow$

Eligibility criteria included the following: (1) homeless according to the Homeless Emergency Assistance and Rapid Transition to Housing (HEARTH) Act definition that includes any person living unsheltered, staying in an emergency shelter, or facing eviction in the next 14 days; (2) age of 50 years or older; (3) English-speaking; and (4) able to provide informed consent as determined by a teach-back mechanism ${ }^{20}$. Participants received $\$ 25$ for the screening and enrollment interview, \$5 for monthly check-ins, and \$15 for follow-up interviews.

\section{Measures}

Outcome Variable. Our primary outcome was self-reported falls in the prior 6 months, assessed at each study interview.
We defined falling as "a sudden, unintentional change in position from an upright posture coming to rest on the floor or ground." For descriptive purposes, among participants who reported a fall, we asked how many times the participant fell and whether they sought medical treatment for their fall.

Independent Variables. Individual Risk Factors. We identified demographic risk factors as time-constant (assessed once at baseline) and other risk factors, health status, and health-related behaviors as time-varying (assessed at each visit).

We assessed age, gender, and race/ethnicity ${ }^{21}$. In our analyses, we dichotomized race as Black versus non-Black. Participants reported their highest educational attainment. We classified participants as having graduated from high school or earned a General Educational Development (GED) certificate versus no high school diploma/GED.

Health Status. Using modified questions from the National Health and Nutrition Examination Survey (NHANES), we asked participants whether a healthcare provider told them they had myocardial infarction, congestive heart failure, stroke, arthritis, diabetes, or chronic lung disease (chronic obstructive pulmonary disease or asthma); we included these as separate variables ${ }^{22}$. If a participant reported a medical condition at any time point, we considered them to have that condition in subsequent visits.

We assessed visual impairment using the Snellen test and defined visual impairment as corrected visual acuity $<20 / 100$ ${ }^{23}$. We defined hearing impairment as self-reported difficulty hearing ${ }^{24}$. To evaluate cognitive impairment, we used the Modified Mini-Mental State Examination (3MS). Those who scored below the 7 th percentile (1.5 standard deviations below a reference cohort mean) or were unable to complete the assessment were defined as cognitively impaired ${ }^{25}$.

We asked participants about their ability to complete activities of daily living (ADLs). We defined an ADL impairment as reporting difficulty with bathing, transferring, toileting, dressing, or eating ${ }^{26}$. We assessed lower extremity function with the Short Physical Performance Battery (SPPB) test and classified those who scored $\leq 10$ as having reduced physical performance ${ }^{27}$. We assessed urinary incontinence in the past 6 months by asking participants whether they had "leaked urine, even a small amount." 28

We measured height and weight and calculated body mass index (BMI), classifying a BMI $\geq 18$ to $<25$ as normal weight, 25 to $<30$ as overweight, and $\geq 30$ as obese. We used the Center for Epidemiologic Studies Depression Scale (CES-D) to assess depressive symptoms; we considered scores $\geq 22$ as indicating depressive symptoms ${ }^{29}$. We assessed pain by asking participants to score their average pain in the past week using a 10-point Likert scale. We categorized pain as mild (0-4), moderate (5-7), and severe $(8-10)^{30}$. We assessed whether participants used an assistive device - such as a cane, crutches, walker, wheelchair, or scooter-in the past 6 months. 


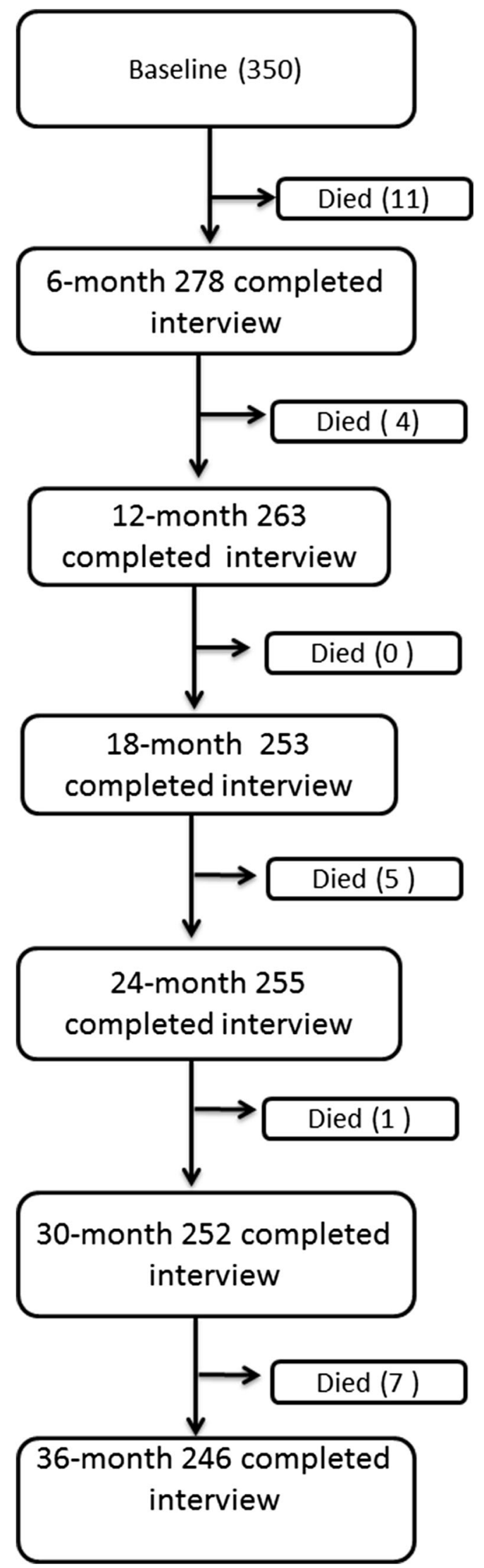

Fig. 1 HOPE HOME sample recruitment and follow-up sample sizes. The number of individuals enrolled at baseline and followed at 6-month intervals over the 36-month follow-up is shown. Deaths between each follow-up are noted. 
Health-Related Behaviors. We classified smoking status using the California Tobacco Survey, categorizing participants as never, current, or former smokers ${ }^{31}$. We asked participants to report how much alcohol they drank and considered those who drank $\geq 6$ drinks on one occasion monthly as heavy drinkers ${ }^{32}$. To assess illicit drug use (cocaine, amphetamines, opioids, and marijuana) in the last 6 months, we used the World Health Organization (WHO)'s Alcohol, Smoking and Substance Involvement Screening Test (ASSIST). We considered a score of $\geq 4$ as indicative of moderate-to-severe use ${ }^{33}$.

\section{Social and Environmental Risk Factors. Social Support. We} used a validated measure of social support, counting the number of people in whom the participant could confide $(0$, $1-5$, or $\geq 6)^{34}{ }^{36}$.

Physical Assault. To assess physical assault, we asked participants: "in the past six months, have you experienced physical violence by another person using an object like a gun or a knife, or did anyone ever slap, hit, punch, kick, choke, or burn you?" 37

Residential Status. To assess exposure to environmental hazards at each visit, we used a residential follow-back calendar in which we asked participants to report each place they had stayed and the number of nights in each setting during the prior 6 months ${ }^{38}$. We considered being unsheltered as indicative of the highest environmental exposure. We defined an unsheltered environment as sleeping outdoors or any place not meant for human habitation (e.g., transit terminal, abandoned building). We categorized participants as having spent any nights versus no nights in unsheltered settings ${ }^{16}$. In preliminary analyses, we evaluated nights unsheltered as a 3-level variable $(0,1-119$, and $12-180$ nights $)$ and as a 6-level variable $(0$, $1-7,8-30,31-90,91-120$, and 121-180 nights). Neither alternative exhibited a dose-response effect. Therefore, we used a dichotomous measure of any nights unsheltered in our analysis.

\section{Statistical Analyses}

To identify risk factors for falls, we chose independent variables based on our hypotheses. We assessed bivariate associations between a priori independent variables and recent falls (i.e., one or more falls in the past 6 months) using generalized estimating equations (GEEs).

We built our multivariable model by including variables with bivariate type $1 p$ values $<0.20$. If a categorical variable had more than two levels, we included all levels in our multivariable model if any type $1 p$ value was $<0.20$. We reduced the model using backward elimination retaining variables with $p$ values $<0.05$ in our final multivariable model. We conducted our analysis in SAS 9.4 using complete case analysis and robust confidence intervals (SAS Institute Inc., Cary, NC, USA, 2017).

In a sensitivity analysis, we assessed whether we had underestimated the probability of falls due to incomplete follow-up or mortality. We examined the prevalence of falls among those (1) with complete follow-up, (2) who had died during followup, or (3) who had not died but had missed any study visits over the 36-month study period. We used GEE to examine whether those who had died or missed visits were more likely to have experienced a fall in the past 6 months than those with complete follow-up.

We included participants with a minimum of two visits. We used weighted linear regression with a second-order polynomial and zero intercept term to plot a trend line.

\section{RESULTS}

\section{Participant Characteristics at Baseline}

The median age was 58.0 (IQR 54.0, 61.0). Of the 350 participants, the majority were men $(77.1 \%)$ and Black $(79.7 \%)$. More than a quarter had less than a high school education (25.7\%; Table 1). Over one quarter was obese $(26.6 \%)$. The majority of participants reported current tobacco use $(65.4 \%)$, and $11.2 \%$ reported heavy drinking. Almost one fifth was cognitively impaired $(18.3 \%)$. The most prevalent substances with problematic use were cocaine $(43.1 \%)$, marijuana $(39.1 \%)$, and opioids $(12.9 \%)$. Approximately one third of the cohort $(32.5 \%)$ reported not having any confidants; $10.1 \%$ experienced physical assault, and $81.7 \%$ had spent a night unsheltered.

\section{Fall Prevalence and Seeking Care for Falls}

At baseline, over one third $(33.7 \%)$ reported one or more falls in the past 6 months (Table 1). Of the 118 participants who reported falling at baseline, $28.0 \%$ reported 4 or more falls, $35.6 \%$ two to three falls, and $36.4 \%$ one fall. One third $(33.1 \%)$ of participants who fell required medical treatment due to a fall.

During the 36-month study, 28 participants died. Of those who survived, 183 completed all six follow-up interviews; 72 completed 4-5 interviews, 32 completed 2-3 interviews, and 21 completed one follow-up interview. We found a higher mean number of falls at baseline among those who died during follow-up (mean 0.42; standard deviation (SD) 0.50) and those who had not died but had missed visits (mean 0.38; SD 0.49) than among those who completed follow-up (mean 0.30; SD $0.46)$.

Of the 350 participants, $218(62.3 \%)$ reported one or more falls in at least one study visit, 107 (30.6\%) reported falls in at least half of the visits, and 34 (9.7\%) reported falls at all visits. 
Table 1 Characteristics of Homeless Adults Aged 50 and Older With and Without Falls in the Past 6 Months at Baseline Interview $(N=350)$

\begin{tabular}{|c|c|c|c|c|}
\hline Characteristics & $\begin{array}{l}\text { Total } \\
(N=350)\end{array}$ & $\begin{array}{l}\text { Experienced falls in } \\
\text { past } 6 \text { months } \\
(N=118)\end{array}$ & $\begin{array}{l}\text { No falls in past } \\
6 \text { months } \\
(N=232)\end{array}$ & $p$ values \\
\hline \multicolumn{5}{|l|}{ Individual risk factors } \\
\hline Age (years), median (interquartile range) & $58.0(54.0,61.0)$ & $58.0(54.0,62.0)$ & $57.5(54.0,61.0)$ & 0.57 \\
\hline Men, $N(\%)$ & $270(77.1)$ & $87(73.7)$ & $183(78.9)$ & 0.28 \\
\hline \multicolumn{5}{|l|}{ Race/ethnicity, $N(\%)$} \\
\hline Black & $279(79.7)$ & $86(72.9)$ & $193(83.2)$ & \multirow[t]{4}{*}{0.11} \\
\hline White & $38(10.9)$ & $18(15.3)$ & $20(8.6)$ & \\
\hline Hispanic & $16(4.6)$ & $8(6.8)$ & $8(3.4)$ & \\
\hline Other & $17(4.9)$ & $6(5.1)$ & $11(4.7)$ & \\
\hline Less than high school diploma/General Education & $90(25.7)$ & $37(31.4)$ & $53(22.8)$ & 0.09 \\
\hline \multicolumn{5}{|l|}{ Development (GED), $N(\%)$} \\
\hline \multicolumn{5}{|l|}{ Health status } \\
\hline Myocardial infarction & $32(9.1)$ & $15(12.7)$ & $17(7.3)$ & 0.10 \\
\hline Congestive heart failure & $25(7.1)$ & $8(6.8)$ & $17(7.3)$ & 0.85 \\
\hline Stroke & $39(11.2)$ & $25(21.4)$ & $14(6.0)$ & $<0.0001$ \\
\hline Arthritis & $156(44.6)$ & $59(50.0)$ & $97(41.8)$ & 0.15 \\
\hline Diabetes & $50(14.3)$ & $18(15.3)$ & $32(13.9)$ & 0.72 \\
\hline Chronic lung disease & $94(26.9)$ & $39(33.1)$ & $55(23.7)$ & 0.06 \\
\hline Visual impairment* & $53(15.9)$ & $19(17.1)$ & $34(15.2)$ & 0.66 \\
\hline Hearing impairment & $124(35.6)$ & 49 (41.9) & $75(32.5)$ & 0.08 \\
\hline Cognitive impairment $(3 \mathrm{MS})^{\dagger}$ & $64(18.3)$ & $20(17.1)$ & $44(19.0)$ & 0.67 \\
\hline$\geq 1$ ADL impairments & $136(38.9)$ & $66(55.9)$ & $70(30.2)$ & $<0.0001$ \\
\hline Physical performance (SPPB test score $\leq 10$ ) & $201(58.4)$ & $84(73.0)$ & $117(51.1)$ & $<0.0001$ \\
\hline Urinary incontinence & $167(48.0)$ & $71(61.2)$ & $96(41.4)$ & 0.0005 \\
\hline \multicolumn{5}{|l|}{ Body mass index, $N(\%)$} \\
\hline$<25$ & $149(43.6)$ & $52(47.3)$ & $97(41.8)$ & \multirow{3}{*}{0.56} \\
\hline 25 to $<30$ & $102(29.8)$ & $29(26.4)$ & $73(31.5)$ & \\
\hline$\geq 30$ & $91(26.6)$ & $29(26.4)$ & $62(26.7)$ & \\
\hline Depressive symptoms; CES-D score $\geq 22, N(\%)$ & $133(38.3)$ & $55(46.6)$ & $78(34.1)$ & 0.02 \\
\hline \multicolumn{5}{|l|}{ Pain severity } \\
\hline Mild & $151(43.4)$ & $43(36.8)$ & $108(46.8)$ & \multirow[t]{3}{*}{0.11} \\
\hline Moderate & $60(17.2)$ & $19(16.2)$ & $41(17.7)$ & \\
\hline Severe & $137(39.4)$ & $55(47.0)$ & $82(35.5)$ & \\
\hline Assistive device & $102(29.1)$ & $50(42.4)$ & $52(22.4)$ & 0.0001 \\
\hline \multicolumn{5}{|l|}{ Health-related behaviors } \\
\hline \multicolumn{5}{|l|}{ Smoking status, $N(\%)$} \\
\hline Non-smoker & $78(22.3)$ & $59(25.4)$ & $19(16.1)$ & \multirow{3}{*}{0.10} \\
\hline Current smoker & $229(65.4)$ & $148(63.8)$ & $81(68.6)$ & \\
\hline Former smoker & $43(12.3)$ & $25(10.8)$ & $18(15.3)$ & \\
\hline Heavy drinking* & $39(11.2)$ & $13(11.1)$ & $26(11.3)$ & 0.97 \\
\hline Cocaine $^{\S}$ & $151(43.1)$ & $57(48.3)$ & $94(40.5)$ & 0.16 \\
\hline Amphetamines & $28(8.0)$ & $10(8.5)$ & $18(7.8)$ & 0.82 \\
\hline Opioids & $45(12.9)$ & $22(18.6)$ & $23(9.9)$ & 0.02 \\
\hline Marijuana & $137(39.1)$ & $58(49.2)$ & $79(34.1)$ & 0.006 \\
\hline \multicolumn{5}{|l|}{ Environmental risk factors, $N(\%)$} \\
\hline \multicolumn{5}{|l|}{ Social support, $N(\%)$} \\
\hline 0 confidants & $113(32.5)$ & $38(32.8)$ & $75(32.3)$ & \multirow[t]{3}{*}{0.02} \\
\hline $1-5$ confidants & $205(58.9)$ & $75(64.7)$ & $130(56.0)$ & \\
\hline $6+$ confidants & $30(8.6)$ & $3(2.6)$ & $27(11.6)$ & \\
\hline Physical assault, past 6 months & $35(10.1)$ & $19(16.2)$ & $16(7.0)$ & 0.007 \\
\hline Any nights spent in unsheltered settings, past 6 months & $286(81.7)$ & $101(85.6)$ & $185(79.7)$ & 0.18 \\
\hline
\end{tabular}

ADL Activities of Daily Living, SPPB Short Physical Performance Battery, CES-D Center for Epidemiologic Studies Depression Scale

*Visual acuity $<20 / 100$ using the Snellen test

†Ognitive impairment defined as a Modified Mini-Mental State Examination score $<7$ th percentile (i.e., 1.5 standard deviations below the demographically adjusted cohort mean)

Greater than or equal to 6 drinks on one occasion $\geq$ once monthly

${ }^{3}$ Moderate-to-severe illicit drug use for the past 6 months defined as a World Health Organization's Alcohol, Smoking and Substance Involvement Screening Test score for cocaine, amphetamines, opioids, and marijuana with a score of $\geq 4$

\section{Factors Associated with Falls}

Those who reported falls at baseline had a higher prevalence of known risk factors for falls than those who had not fallen (Table 1). People with falls were significantly more likely to have less than a high school education, a history of stroke, difficulty with ADLs, mobility impairment, use of assistive device, increased urinary incontinence, and depressive symptoms. We found that those who fell were more likely to have moderate-to-high risk opioid and marijuana use, fewer social confidants, have spent at least one night unsheltered, or experienced physical assault.

In models adjusted for key covariates, individual risk factors associated with significantly higher odds of falls included older age (adjusted odds ratio (AOR) 1.03, confidence interval (CI) 1.00-1.06), being a woman (AOR $1.45,95 \%$ CI 1.02 2.04), having non-Black race (AOR 1.65, 95\% CI 1.12-2.43), 
having a history of stroke (AOR 2.17, 95\% CI 1.42-3.32), reporting an ADL impairment (AOR 1.99, 95\% CI 1.512.63), urinary incontinence (AOR 1.40, 95\% CI 1.07-1.81), and use of an assistive device (AOR 1.86, 95\% CI 1.39-2.50) (Table 2).

Moderate-to-severe marijuana use (AOR 1.93, 95\% CI 1.47-2.55) and moderate-to-severe opioid use (AOR 1.64, 95\% CI 1.02-2.65) were associated with increased odds of falling. Experiencing physical assault (AOR 1.67, 95\% CI 1.18-2.37) and spending any night unsheltered (AOR 1.42, 95\% CI 1.10-1.83) in the last 6 months were as well.

In a sensitivity analysis, we found that those who had died during study follow-up (AOR 1.35, 95\% CI 0.56-3.28) or

Table 2 Odds of Experiencing Falls in the Past 6 Months over 3 Years in the GEE Model Among Adults Aged $\geq 50$ Years Who Were Homeless at Baseline 2013-2014

\begin{tabular}{|c|c|c|}
\hline$\overline{\text { Variables }}$ & $\begin{array}{l}\text { Unadjusted odds } \\
\text { ratio }(\mathrm{OR})(95 \% \\
\text { CI)* }\end{array}$ & $\begin{array}{l}\text { Adjusted odds } \\
\text { ratio (AOR) } \\
(95 \% \text { CI) }\end{array}$ \\
\hline \multicolumn{3}{|l|}{ Individual risk factors } \\
\hline Age (continuous years) & $1.03(1.00-1.05)$ & $1.03(1.00-1.06)$ \\
\hline Women & $1.59(1.11-2.27)$ & $1.45(1.02-2.04)$ \\
\hline Non-Black & $1.68(1.15-2.45)$ & $1.65(1.12-2.43)$ \\
\hline$<$ High school diploma/ & $1.37(0.94-2.01)$ & - \\
\hline \multicolumn{3}{|l|}{ GED } \\
\hline \multicolumn{3}{|l|}{ Health status } \\
\hline Myocardial infarction & $2.15(1.30-3.57)$ & - \\
\hline Congestive heart failure & $1.70(0.98-2.94)$ & - \\
\hline Stroke & $3.36(2.07-5.47)$ & $2.17(1.42-3.32)$ \\
\hline Arthritis & $1.44(1.04-2.00)$ & - \\
\hline Diabetes & $0.74(0.49-1.10)$ & - \\
\hline Chronic lung disease & $1.61(1.16-2.24)$ & - \\
\hline Hearing impairment & $1.49(1.07-2.08)$ & - \\
\hline$\geq 1$ ADL impairments & $3.06(2.34-3.99)$ & $1.99(1.51-2.63)$ \\
\hline Physical performance & $1.82(1.29-2.56)$ & - \\
\hline \multicolumn{3}{|l|}{$($ SPPB test score $\leq 10)$} \\
\hline Urinary incontinence & $2.23(1.71-2.91)$ & $1.40(1.07-1.81)$ \\
\hline Depressive symptoms & $1.73(1.31-2.28)$ & - \\
\hline \multicolumn{3}{|l|}{ (CES-D score $\geq 22$ ) } \\
\hline \multicolumn{3}{|l|}{ Pain severity } \\
\hline Moderate & $1.74(1.26-2.40)$ & \\
\hline Severe & $2.51(1.83-3.44)$ & \\
\hline Assistive device & $2.81(2.11-3.75)$ & $1.86(1.39-2.50)$ \\
\hline \multicolumn{3}{|l|}{ Health-related behaviors } \\
\hline Current smoker & $1.30(0.96-1.77)$ & \\
\hline Heavy drinking ${ }^{\dagger}$ & $1.63(1.08-2.47)$ & - \\
\hline Cocaine ${ }^{\ddagger}$ & $1.36(1.00-1.86)$ & _- \\
\hline Opioids & $2.13(1.35-3.36)$ & $1.64(1.02-2.65)$ \\
\hline Marijuana & $1.85(1.40-2.42)$ & $1.93(1.47-2.55)$ \\
\hline \multicolumn{3}{|l|}{ Environmental risk factors } \\
\hline \multicolumn{3}{|l|}{ Social support } \\
\hline $1-5$ confidants & $1.11(0.84-1.46)$ & - \\
\hline$\geq 6$ confidants & $0.65(0.36-1.15)$ & - \\
\hline Physical assault, past & $2.28(1.65-3.17)$ & $1.67(1.18-2.37)$ \\
\hline 6 months & & \\
\hline $\begin{array}{l}\text { Any nights spent in } \\
\text { unsheltered settings, past } \\
6 \text { months }\end{array}$ & $1.49(1.16-1.91)$ & $1.42(1.10-1.83)$ \\
\hline
\end{tabular}

GED General Education Development, ADL Activities of Daily Living, SPPB Short Physical Performance Battery, CES-D Center for Epidemiologic Studies Depression Scale

* Only bivariate variables with any type $1 p$ values $<0.20$ are shown, and these were entered in the starting multivariate model

tGreater than or equal to 6 drinks on one occasion $\geq$ once monthly $\$$ Moderate-to-severe illicit drug use for the past 6 months defined as a World Health Organization's Alcohol, Smoking and Substance Involvement Screening Test score for cocaine, amphetamines, opioids, and marijuana with a score of $\geq 4$ who survived to study follow-up but had missed visits (AOR $1.24,95 \%$ CI $0.89-1.72$ ) were more likely to experience falls.

\section{DISCUSSION}

In this longitudinal study of adults aged 50 and older who were homeless at study enrollment, we found a high prevalence of falls. Despite a median age of 58 years, study participants reported a prevalence of falls higher than older adults with a mean age of 78 in the general population ${ }^{3}$. Many participants fell repeatedly throughout the 3-year study period; over a third of the cohort reported falls in at least half of their study visits. We found an association between falls and several factors known to increase fall risk within the general population, including older age, gender, functional impairment, urinary incontinence, use of an assistive device, and stroke.

Our findings indicate that the increased risk of falls in homeless older adults results, in part, from a high prevalence of geriatric conditions (e.g., functional and urinary impairment) and substance use (e.g., problematic opioid use) known to increase fall risk ${ }^{2}$. Some of these risk factors may be modifiable via physical and occupational therapy, although it is more difficult to intervene while someone is experiencing homelessness. As the average age of the homeless population continues to increase, the population will have increasing prevalence of geriatric risk factors ${ }^{39}$.

We identified the following novel risk factors: using marijuana, experiencing physical assault, and spending time unsheltered that contributed to the high fall prevalence in our population. Both opioid use and marijuana use were associated with increased odds of falling. Opioid use is associated with increased fall risk among older adults in the general population ${ }^{40},{ }^{41}$. However, despite research on marijuana use and injuries in community-dwelling older adults, little is known about how marijuana use impacts falls ${ }^{42}{ }^{44}$. Marijuana-like opioidsmay increase falls by affecting the sensorium, inducing dizziness, confusion, and drowsiness ${ }^{42},{ }^{45}$. We found a high prevalence of marijuana use among study participants. People born in the study's age cohort have had high prevalence of marijuana use their whole lives, including in older adulthood $46 \_48$. As marijuana use among older adults increases, due to changes in legal status and cohort effects, there may be increased falls associated with its use.

Experiencing physical assault is common among older adults who are homeless ${ }^{16}$. Physical assault can increase fall risk directly (as a complication of assault), or indirectly, by causing injuries that enhance underlying individual vulnerabilities associated with falls ${ }^{16}$. Future research should evaluate the role of marijuana use and physical assault in falls among housed older adults to determine whether these risk factors are unique to older adults experiencing homelessness.

People who are unsheltered have increased exposure to unsafe environments, with minimal control. They may stay in isolated locations with uneven surfaces and physical 
barriers, such as abandoned buildings, under bridges, or along highways. Unsheltered environments lack lighting or protection against environmental hazards. Avoiding falls requires intact executive function and physical agility to be able to process external stimuli and modify movements to remain upright ${ }^{49}$. For older adults with vulnerabilities — such as those common among homeless older adults - small external triggers (e.g., rain, sidewalk debris, or uneven surfaces) may precipitate falls. Housed older adults are able to modify their behaviors to avoid high-risk environmental exposures that predispose them to falls. For example, they can decrease how often they walk outside on uneven surfaces or minimize their public transit use. In contrast, adults living in unsheltered settings have less ability to avoid high-risk environmental exposures ${ }^{50}$.

Our finding that non-Black race was associated with increased falls is consistent with research in housed adults ${ }^{51},{ }^{52}$. Homelessness is caused by an interaction between structural factors and individual risk factors. Because Black Americans face structural racism, Black Americans with less individual vulnerability (such as substance use and mental health disabilities) are at risk of homelessness. While we adjusted for these conditions, there may be unmeasured confounders that we were unable to account for ${ }^{1},{ }^{53}$.

\section{Limitations}

Our study has several limitations. We rely on 6-month recall of falls. Other studies of falls in older adults use timeframes that range from monthly to biennial ${ }^{54},{ }^{55}$. Participants without complete study follow-up had a higher prevalence of falls, indicating that our model may have underestimated the odds of experiencing falls. We did not ask about prescribed medications and could not report on the role of polypharmacy. We conducted the study in the San Francisco Bay Area, where $67 \%$ of people experiencing homelessness live unsheltered, compared to $5 \%$ in both New York and Boston ${ }^{56}$. Studies in cities with lower proportions of unsheltered homelessness may report lower rates of falls. Among individuals who are unsheltered, there are a wide variety of environments that may affect fall risk. We did not have detailed data on the variety of environments in which unsheltered homeless people stayed and cannot assess the risk of these different exposures.

\section{CONCLUSION}

Older homeless adults have a high rate of falls, similar to those of adults 20 years older. The increased risk is due to a high prevalence of individual risk factors and environmental exposures. Identifying people at high risk of falls could allow targeted interventions, such as providing shelter, low-height accessible beds, counseling on marijuana and opioid use, and physical therapy. For older adults who live unsheltered, there are nascent efforts to have occupational therapists visit unsheltered settings to reduce fall risk by employing reflective tape and anchoring unstable environmental elements ${ }^{57},{ }^{58}$. Finally, reducing unsheltered homelessness - via either increased shelters or, ideally, increased long-term housing - could decrease the number of falls in this high-risk population.

Contributors: We gratefully acknowledge our colleagues Claudia Ponath, Pamela Olsen, John Weeks, Stephen King, and Kenneth Perez for their invaluable contributions to the HOPE HOME study. The authors also thank the staff at St. Mary's Center and the HOPE HOME Community Advisory Board for their guidance and partnership.

Corresponding Author: Margot Kushel, MD; Center for Vulnerable Populations, University of California, San Francisco, UCSF Box 1364, San Francisco, CA 94143, USA (e-mail: margot.kushel@ucsf.edu).

Funding Information This study was funded by grants from the National Institute on Aging at the National Institutes of Health (R01AG041860, K24AG046372, K23AG045290, K76AG057016) and the American Federation for Aging Research (K76AG057016). These funding sources had no role in the preparation, review, or approval of the manuscript.

\section{Compliance with Ethical Standards:}

Conflict of Interest: The authors declare that they do not have a conflict of interest.

Disclaimer/Disclosures: The views expressed here/in this manuscript are those of the authors and do not necessarily represent the views of the National Institute on Aging at the National Institutes of Health or the American Federation for Aging Research.

\section{REFERENCES}

1. Henry M, Watt R, Rosenthal L, Shivji A. The 2017 Annual Homeless Assessment Report (AHAR) to Congress. Washington: DC: The U.S. Department of Housing and Urban Development: Office of Community Planning and Development;2017.

2. Brown RT, Hemati K, Riley ED, et al. Geriatric Conditions in a Population-Based Sample of Older Homeless Adults. Gerontologist. 2017;57(4):757-766.

3. Brown RT, Kiely DK, Bharel M, Mitchell SL. Geriatric syndromes in older homeless adults. J Gen Intern Med. 2012;27(1):16-22.

4. Cigolle CT, Ha J, Min LC, et al. The epidemiologic data on falls, 19982010: more older Americans report falling. JAMA Intern Med. 2015;175(3):443-445.

5. Florence CS, Bergen G, Atherly A, Burns E, Stevens J, Drake C. Medical Costs of Fatal and Nonfatal Falls in Older Adults. J Am Geriatr Soc. 2018;66(4):693-698.

6. Friedman SM, Munoz B, West SK, Rubin GS, Fried LP. Falls and fear of falling: which comes first? A longitudinal prediction model suggests strategies for primary and secondary prevention. J Am Geriatr Soc. 2002;50(8):1329-1335.

7. King MB, Tinetti ME. Falls in community-dwelling older persons. $J$ Am Geriatr Soc. 1995;43(10):1146-1154

8. Tinetti ME, Inouye SK, Gill TM, Doucette JT. Shared risk factors for falls, incontinence, and functional dependence. Unifying the approach to geriatric syndromes. JAMA. 1995;273(17):1348-1353.

9. Tinetti ME. Preventing Falls in Elderly Persons. $N$ Engl $\mathrm{J}$ Med. 2003;348(1):42-49.

10. Tinetti ME, Baker DI, McAvay G, et al. A multifactorial intervention to reduce the risk of falling among elderly people living in the community. $N$ Engl J Med. 1994;331(13):821-827.

11. Paliwal Y, Slattum PW, Ratliff SM. Chronic Health Conditions as a Risk Factor for Falls among the Community-Dwelling US Older Adults: A ZeroInflated Regression Modeling Approach. Biomed Res Int. 2017;2017:5146378. 
12. Li W, Keegan TH, Sternfeld B, Sidney S, Quesenberry CP, Jr., Kelsey JL. Outdoor falls among middle-aged and older adults: a neglected public health problem. Am J Public Health. 2006;96(7):1192-1200.

13. Kelsey JL, Berry SD, Procter-Gray E, et al. Indoor and outdoor falls in older adults are different: the maintenance of balance, independent living, intellect, and Zest in the Elderly of Boston Study. J Am Geriatr Soc. 2010;58(11):2135-2141.

14. Inouye SK, Studenski S, Tinetti ME, Kuchel GA. Geriatric syndromes: clinical, research, and policy implications of a core geriatric concept. J Am Geriatr Soc. 2007;55(5):780-791.

15. Spinelli MA, Ponath C, Tieu L, Hurstak EE, Guzman D, Kushel M. Factors associated with substance use in older homeless adults: Results from the HOPE HOME study. Subst Abus. 2017:38(1):88-94.

16. Tong MS, Kaplan LM, Guzman D, Ponath C, Kushel MB. Persistent Homelessness and Violent Victimization Among Older Adults in the HOPE HOME Study. J Interpers Violence. 2019:886260519850532.

17. Lee CT, Guzman D, Ponath C, Tieu L, Riley E, Kushel M. Residential patterns in older homeless adults: Results of a cluster analysis. Soc Sci Med. 2016;153:131-140.

18. Burnam MA, Koegel P. Methodology for obtaining a representative sample of homeless persons: The Los-Angeles skid row study. Eval Rev. 1988;12(2): 117-152.

19. Brown RT, Goodman L, Guzman D, Tieu L, Ponath C, Kushel MB. Pathways to Homelessness among Older Homeless Adults: Results from the HOPE HOME Study. PLOS ONE. 2016;11(5):e0155065

20. Dunn LB, Jeste DV. Enhancing informed consent for research and treatment. Neuropsychopharmacology. 2001;24(6):595-607.

21. U.S. Census Bureau. 2010 Census of Population Housing. Available at: https://www.census.gov/programs-surveys/decennial-census/decade. 2010.html. Accesssed August $27^{\text {th }} 2019$.

22. Teno JM, Licks S, Lynn J, et al. Do advance directives provide instructions that direct care? SUPPORT Investigators. Study to Understand Prognoses and Preferences for Outcomes and Risks of Treatment. $J$ Am Geriatr Soc. 1997;45(4):508-512.

23. U.S. Preventive Services Task Force (USPSTF), Siu, AL, Bibbins-Domingo, $\mathrm{K}$, et al. Screening for impaired visual acuity in older adults: U.S. Preventive Services Task Force recommendation statement. Ann Intern Med. 2009;151(1):37-43, W10.

24. Moyer VA. Screening for hearing loss in older adults: U.S. Preventive Services Task Force recommendation statement. Ann Intern Med. 2012;157(9):655-661.

25. Bland RC, Newman SC. Mild dementia or cognitive impairment: the Modified Mini-Mental State examination (3MS) as a screen for dementia. Can J Psychiatry. 2001;46(6):506-510.

26. Katz S. Assessing self-maintenance: activities of daily living, mobility, and instrumental activities of daily living. $J$ Am Geriatr Soc. 1983;31(12):721-727.

27. Guralnik JM, Simonsick EM, Ferrucci L, et al. A short physical performance battery assessing lower extremity function: association with self-reported disability and prediction of mortality and nursing home admission. J Gerontol. 1994;49(2):M85-94.

28. Brown JS, Bradley CS, Subak LL, et al. The sensitivity and specificity of a simple test to distinguish between urge and stress urinary incontinence. Ann Intern Med. 2006; 144(10):715-723.

29. Radloff LS. The CES-D Scale: A self-report depression scale for research in the general population. Applied Psychological Measurement. 1977;1(3):385-401.

30. Cleeland CS, Ryan KM. Pain assessment: global use of the Brief Pain Inventory. Ann Acad Med Singapore. 1994;23(2):129-138.

31. Al-Delaimy, WK; Edland, S; Pierce, JP; et al. California Tobacco Survey (CTS) 2008. Available at: https://doi.org/10.6075/JOKW5CX7. Accessed August $27^{\text {th }} 2019$.

32. Babor TF, Higgins-Biddle JC, Saunders JB, Monteiro MG. The Alcohol Use Disorders Identification Test: Guidelines for Use in Primary Care. World Health Organization;2001

33. Humeniuk R, Henry-Edwards S, Ali R, Poznyak V, Monteiro M. The Alcohol, Smoking and Substance Involvement Screening Test (ASSIST): Manual for use in primary care. Geneva: World Health Organization;2010.

34. Gielen AC, O'Campo PJ, Faden RR, Kass NE, Xue X. Interpersonal conflict and physical violence during the childbearing year. Soc Sci Med. 1994;39(6):781-787.

35. Gielen AC, McDonnell KA, Wu AW, O'Campo P, Faden R. Quality of life among women living with HIV: the importance violence, social support, and self care behaviors. Soc Sci Med. 2001;52(2):315-322.
36. Riley ED, Cohen J, Knight KR, Decker A, Marson K, Shumway M. Recent violence in a community-based sample of homeless and unstably housed women with high levels of psychiatric comorbidity. Am J Public Health. 2014;104(9): 1657-1663.

37. Straus MA, Hamby SL, Boney-McCoy SUE, Sugarman DB. The Revised Conflict Tactics Scales (CTS2): Development and Preliminary Psychometric Data. J Fam Issues. 1996;17(3):283-316.

38. Tsemberis S, McHugo G, Williams V, Hanrahan $\mathbf{P}$, Stefancic A. Measuring homelessness and residential stability: The residential timeline follow-back inventory. J Community Psychol. 2006;35(1):29-42.

39. Culhane DP, Treglia D, Byrne T, et al. The Emerging Crisis of Aged Homelessness: A Multi-Site Research Project: Could Housing Solutions Be Funded by Avoidance of Excess Shelter, Hospital, and Nursing Home Costs? 2019. Available at: https://www.aisp.upenn.edu/wp-content/ uploads/2019/01/Emerging-Crisis-of-Aged-Homelessness-1.pdf. Accessed August $27^{\text {th }} 2019$.

40. Daoust R, Paquet J, Moore L, et al. Recent opioid use and fall-related injury among older patients with trauma. CMAJ. 2018;190(16):E500e506.

41. Rolita L, Spegman A, Tang X, Cronstein BN. Greater number of narcotic analgesic prescriptions for osteoarthritis is associated with falls and fractures in elderly adults. J Am Geriatr Soc. 2013;61(3):335-340.

42. Abuhasira R, Schleider LB, Mechoulam R, Novack V. Epidemiological characteristics, safety and efficacy of medical cannabis in the elderly. Eur $J$ Intern Med. 2018;49:44-50.

43. Choi NG, Marti CN, DiNitto DM, Choi BY. Older adults' marijuana use, injuries, and emergency department visits. Am J Drug Alcohol Abuse. 2018;44(2):215-223.

44. Barrio G, Jiménez-Mejías E, Pulido J, Lardelli-Claret P, Bravo MJ, de la Fuente L. Association between cannabis use and non-traffic injuries. Accident Analysis \& Prevention. 2012;47:172-176.

45. Briscoe J, Casarett D. Medical Marijuana Use in Older Adults. J Am Geriatr Soc. 2018;66(5):859-863.

46. Lloyd SL, Striley CW. Marijuana Use Among Adults 50 Years or Older in the 21 st Century. Gerontology and Geriatric Medicine. 2018;4:2333721418781668.

47. Dinitto DM, Choi NG. Marijuana use among older adults in the U.S.A. user characteristics, patterns of use, and implications for intervention. Int Psychogeriatr. 2011;23(5):732-741.

48. Johnson PB, Sung H-E. Substance Abuse among Aging Baby Boomers: Health and Treatment Implications. J Addict Nurs. 2009;20(3):124-126.

49. Nowak A, Hubbard RE. Falls and frailty: lessons from complex systems. $J$ R Soc Med. 2009;102(3):98-102.

50. Clemson L, Cusick A, Fozzard C. Managing risk and exerting control: determining follow through with falls prevention. Disabil Rehabil. 1999;21(12):531-541.

51. Sun DQ, Huang J, Varadhan R, Agrawal Y. Race and fall risk: data from the National Health and Aging Trends Study (NHATS). Age Ageing. 2016;45(1): 120-127.

52. Hanlon JT, Landerman LR, Fillenbaum GG, Studenski S. Falls in African American and White Community-Dwelling Elderly Residents. The Journals of Gerontology: Series A. 2002;57(7):M473-M478.

53. Gee GC, Ford CL. STRUCTURAL RACISM AND HEALTH INEQUITIES: Old Issues, New Directions. Du Bois Rev. 2011;8(1):115-132.

54. Blackwood J. Cognitive Function and Falls in Older Adults With Type 2 Diabetes Mellitus. J Geriatr Phys Ther.

55. Leveille SG, Kiel DP, Jones RN, et al. The MOBILIZE Boston Study: design and methods of a prospective cohort study of novel risk factors for falls in an older population. BMC Geriatr. 2008;8:16.

56. Bay Area Council Economic Institute. Bay Area Homelessness: A Regional View of A Regional Crisis. 2019. Available at: http://www. bayareaeconomy.org/files/pdf/BayAreaHomelessnessReport.pdf. Accessed August $27^{\text {th }} 2019$.

57. Los Angeles County Department of Health Services (DHS). Housing for Health. 2019. Available at: http://dhs.lacounty.gov/wps/portal/dhs/ housingforhealth. Accessed Nov 8th 2019.

58. Henwood B. Piloting the CAPABLE model in Permanent Supportive Housing. 2019. Available at: https://sc-ctsi.org/funding/awardees/benjamin-henwood-1. Accessed Nov 8th 2019.

Publisher's Note Springer Nature remains neutral with regard to jurisdictional claims in published maps and institutional affiliations. 